RESEARCH ETHICS

\title{
How should we measure informed choice? The case of cancer screening
}

\author{
R G Jepson, J Hewison, A G H Thompson, D Weller
}

J Med Ethics 2005;31:192-196. doi: 10.1136/jme.2003.005793

Informed choice is increasingly recognised as important in supporting patient autonomy and ensuring that people are neither deceived nor coerced. In cancer screening the emphasis has shifted away from just promoting the benefits of screening to providing comprehensive information to enable people to make an informed choice. Cancer screening programmes in the UK now have policies in place which state that it is their responsibility to ensure that individuals are making an individual informed choice. There is a need to evaluate whether such policies mean that those people invited for screening are making informed choices, and how comprehensive information affects other variables such as uptake, cost effectiveness, and satisfaction. At the present time, there is no validated measure of informed choice in cancer screening. Such a measure could be used to evaluate the effectiveness of interventions to increase informed choice and levels of informed choice in a population invited for screening. It could encourage health professionals to be accountable. Factors important when measuring informed choice in cancer screening include an individual's understanding of the limitations of screening, the ability to make an autonomous choice, and the difference between choice and behaviour.

See end of article for authors' affiliations

\section{Correspondence to:} Ms R Jepson, Division of Community Health Sciences-General Practice, University of Edinburgh, 20 West Richmond Street Edinburgh EH8 9DX, UK; ruth.jepson@ed.ac.uk

Received 15 July 2003

In revised form

9 December 2003

Accepted for publication

19 January 2004
T heories of postmodernism suggest that people have increasingly taken on the role of individualised consumers who place high value on choice and particularly the concept of informed choice. Healthcare professionals are among the leading sources of choices from the cradle to the grave. ${ }^{1}$ In recent years, informed choice has found support in many areas of healthcare including cancer screening. ${ }^{23}$

Cancer screening for many years has been viewed as a public health policy aimed at disease prevention. In the UK, for example, once a woman reaches 50 years of age she is automatically invited to be screened for breast cancer (providing there are no contraindications). Until recently screening has been promoted as a beneficial, preventative activity that all eligible people should participate in. The benefits of screening for cancer were deemed to be so great that harms and limitations were overlooked. ${ }^{4}$ However, informed choice has now been accepted by screening policy makers and is now being considered alongside more conventional screening parameters, such as quality assurance procedures and improvements in survival. For example, the second report of the National Screening Committee (NSC) states: "There is a responsibility to ensure that people who accept an invitation do so on the basis of informed choice, and appreciate that in accepting an invitation or participating in a programme to reduce their risk of a disease there is a risk of an adverse outcome. ${ }^{\prime 4}$ In addition, recent guidance from the General Medical Council (GMC) states that doctors must ensure that anyone considering whether to consent to screening can make a properly informed decision.

\section{Individual choice within cancer screening} programmes

In order to maximise effectiveness, the main focus of screening programmes is to have the highest coverage and uptake of the population as possible. As such, many policies in place in the UK encourage health professionals to increase uptake rather than informed choice. For cervical screening, general practitioners get paid an incentive if they achieve high levels of uptake in their practice. It has been argued that target payments work against the spirit of enabling individuals to make an informed choice about whether they want to be screened. ${ }^{6}$ However, there is concern that increasing informed choice may reduce uptake, resulting in programmes no longer being cost effective.

Even when it is accepted that screening has a net beneficial effect, one of its inherent limitations is that some individuals will be harmed and others will benefit. Moral conflicts and concerns over patient rights arise where an intervention has the potential to cause both benefit and harm to an individual. ${ }^{7}$ In recent years all areas of health care have become increasingly interested in the concept of informed choice and the rights of the individual. The focus of informed choice is on disclosure of risk information to promote individual autonomy. The concept is grounded in liberal philosophy, which implies that individual rights are paramount. ${ }^{8}$ However, public health policies such as screening are grounded in the philosophy of utilitarianism and based on population outcomes such as reduction in the burden of disease.

The purpose of this paper is not to try and place a value on the relative importance of these two theories. Neither is it attempting to evaluate

Abbreviations: GMC, General Medical Council; NSC, National Screening Committee. 
whether they can be compatible. The main aim of this paper is to propose the main elements that are important to consider in the measurement of informed choice within existing cancer screening programmes.

The concept of informed choice was originally developed within the context of decisions about treatments. It is now seen as being important within public health programmes and is positioned among other outcomes such as uptake and reduction of the burden of disease, all of which have resource implications. There are finite resources in any health programme; thus all of the important aspects within that programme-quality control, high uptake, good educational materials, staff development programmes, and promoting informed choice-must ultimately compete with one another. In addition, the provision of information may also affect other outcomes both positively (for example, a decrease in anxiety) and negatively (a decrease in uptake). There is concern that there will be tension between promoting informed choice and promoting uptake. ${ }^{9}$ This concern has not, as yet, been borne out by any empirical evidence. In one systematic review of informed choice interventions in screening, it was concluded that promoting informed choice did not appear to have any impact on uptake, ${ }^{10}$ whereas another showed that the disclosure of information on individual risk increased screening uptake. ${ }^{11}$ However, as the authors note, this should not be interpreted as making an informed choice.

\section{WHAT IS MEANT BY INFORMED CHOICE?}

The concept of informed choice is based on the doctrine of informed consent. The expression "informed choice" not "informed consent" is principally used within health screening because people are normally invited to participate, and they choose (to a greater or lesser extent) whether to do so or not. They may never have any contact with a health professional if they decide not to participate. We would argue that consent implies more active decision making following some contact and discussion with a health professional.

Reasons for encouraging informed choice include supporting patient autonomy and providing reassurance that patients are neither deceived nor coerced. ${ }^{12}$ However, what is not known is the extent to which the provision of unbiased, comprehensive screening information increases informed choice. The fundamental goal in enhancing patient choice is to enable patients to come to an autonomous decision which reflects their personal preferences. The goal of enhancing choice cannot, therefore, be to encourage a specific choice to be made. ${ }^{13}$ Several recent definitions related to informed choice are given in table 1 .

As can been seen from table 1 , definitions vary both in terminology and in content. The terms "choice" and "decision" are both used in the literature to denote

\begin{tabular}{|c|c|}
\hline Terms & Definition \\
\hline Informed choice & $\begin{array}{l}\text { One that is informed, consistent with the decision } \\
\text { maker's values, and behaviourally implemented }\end{array}$ \\
\hline Informed decision & $\begin{array}{l}\text { One where a reasoned choice is made by a } \\
\text { reasonable individual using relevant information } \\
\text { about the advantages and disadvantages of all } \\
\text { the possible courses of action, in accord with the } \\
\text { individual's beliefs } s^{5}\end{array}$ \\
\hline $\begin{array}{l}\text { Autonomous } \\
\text { choice }\end{array}$ & $\begin{array}{l}\text { One which occurs when people act (1) intentionally, } \\
\text { (2) with understanding, and ( } 3 \text { ) without controlling } \\
\text { influences that determine their actions }{ }^{16}\end{array}$ \\
\hline $\begin{array}{l}\text { Evidence based } \\
\text { patient choice }\end{array}$ & $\begin{array}{l}\text { The use of evidence based information as a way of } \\
\text { enhancing people's choices when these people are } \\
\text { patients }\end{array}$ \\
\hline
\end{tabular}

essentially the same underlying concept. In addition, behavioural implementation of the choice is a required criteria in one definition ${ }^{14}$ but not in others. Definition of what it means to make an informed choice is difficult; perhaps no definition can fully explain the concept. The purpose of this paper is to understand the factors that affect both "informedness" and choice.

To enable a person to make an informed choice, he or she needs to be provided with adequate, high quality, relevant, unbiased information of all the consequences of making her/ his choice. For example, the GMC proposes that people need the following information in order to make such an informed decision (or choice) in screening:

- the purpose of the screening;

- the likelihood of positive/negative findings and possibility of false positive/negative results;

- the uncertainties and risks attached to the screening process;

- any significant medical, social, or financial implications of screening for the particular condition or predisposition;

- follow up plans, including availability of counselling and support services. ${ }^{5}$

Definitions of what comprise an informed choice, however, might differ according to a person's perspective. For the health professional, an informed choice may be a rational one, where the individual chooses the option with the best clinical outcomes. For the individual person, an informed choice may be one where they feel more satisfied and less anxious about their decision. To feel informed, individuals may want information on how people who have been through a negative experience have coped and what it is like to experience a particular health state. ${ }^{17}$

\section{Choice and information}

The provision of relevant, high quality information is assumed by some to be sufficient to enable people to make an informed choice. However, for a person to make an informed choice much more is needed than the provision of information. The information needs to have been read and understood. In addition, a person must be able to choose freely between different options and to carry out their intended choice.

The relation between the way information is presented and the choices people make also needs to be considered. Provision of information may not be value free and may be used to direct choice. For example, the way that "logically equivalent" information is presented (framed) has the potential to manipulate consumer decisions. ${ }^{18}$ Additionally, a qualitative study reported that choices in many evidence based maternity leaflets were interpreted by patients as indicting "right" and "wrong" choices. The authors concluded that the normative culture in which leaflets on informed choice were being introduced resulted in informed compliance rather than informed choice. ${ }^{19}$ Thus people may be informed but not feel free to make a choice that is not consistent with normative beliefs.

\section{Choice and autonomy}

The provision of information may enable a person to become informed, but it may play little part in enabling an autonomous choice to be made. Although comprehensive information is a prerequisite for informed choice, a person can be informed without having (or indeed wanting) a choice. Equally, a person may want to make an autonomous choice without the use of information.

It can be argued that there are three main aspects of choice in the context of healthcare in general and screening in 
particular. Firstly, there should be options available to choose from and people should know that they have a choice. Secondly, the person should be able to carry out their preferred choice. There may be barriers (for example, disability, language, poor health, access), which mean that, even though a choice is available in principle, it cannot be carried out in practice. Thirdly, the choice should be autonomous. The predominant theory of autonomy in relation to patient choice and healthcare is proposed by Fadden and Beauchamp. ${ }^{16}$ They define an autonomous action as one which is performed intentionally, with understanding, and without controlling actions. However, this definition was largely for people making decisions about different treatment options. Whether such notions of autonomy can exist within public health policies is perhaps open to debate.

\section{Informed choice and shared decision making}

Informed shared decision making has been described as "decisions that are shared by doctor and patient and informed by best evidence, not only about risks and benefits but also patient specific characteristics and values" ${ }^{\prime 20}$ In shared decision making, both the health professional and the patient are assumed to have a legitimate investment in the treatment decisions. ${ }^{21}$ At the present time most of the decisions regarding cancer screening in the UK are made outwith the patient-doctor consultation. Therefore, consideration of the implications of shared decision making on patient autonomy are not of great relevance. Cancer screening (with the exception of cervical screening) takes place at the level of organised, centralised screening programmes, with modest interaction between screening invitees and health professionals.

THE RELATION BETWEEN CHOICE AND BEHAVIOUR When measuring informed choice or informed decision making, it should not be assumed that behaviour reflects the initial choice. For example, even though a person chooses to participate in screening, participation may not eventuate. The difference between screening behaviour and screening choice may be due to predictable factors (for example, choices available and barriers to participation) and unpredictable factors (for example, acute illness, forgetfulness, competing priorities, and holidays). The disparity between choice and behaviour may also have a temporal element to it; the shorter the timespan between making the choice and carrying out the behaviour, the smaller the impact of unpredictable factors. A person who is invited to be screened opportunistically during a GP visit is unlikely to have their choice affected by unpredictable factors. However, even when there is only a small time lapse between choice and behaviour, using behaviour as a proxy for choice might still not be appropriate. For example, the person who makes a choice at the same time as being offered the test may feel more coerced and have less autonomy.

The relation between choice and behaviour may also partly be dependent on the organisation of screening programmes. In the UK, for example, women are invited via their GP for cervical screening. For breast screening, women are invited via the Breast Screening Programme. To undergo either of these screening tests, most people would have to travel, which introduces external factors such as access, missing the bus, and so on. For colorectal cancer screening, however, people are sent the test and it is self administered. Thus concerns relating to access are less likely to affect those invited to participate in colorectal cancer screening. These issues also relate to the provider of screening services; for example, cervical screening is organised through GPs, whereas colorectal and breast screening are organised centrally.
When defining and measuring choice, therefore, distinctions need to be made between the choice and the final behaviour. People may be well informed but still not be able to carry out their preferred choice. Even if they can carry out their choice, and intend to do so, external factors may prevent them from doing so. Examples are given below of possible scenarios, which illustrate the difference between intention and behaviour. By measuring intention before the behaviour we can see whether the initial intention to be screened was informed.

\section{Scenario 1}

A woman living in rural Scotland is invited to attend for mammography screening at one of the screening vans. She gets information on the risks and benefits, wishes to go, but on the day of the screening is sick. She had made an informed choice to attend, but was not able to carry out that choice. The next time she receives her invitation she is on holiday, and does not have a car to be able to travel to another site. She decides not to go, even though her preferred choice is to attend.

\section{Scenario 2}

A male amputee is sent screening tests for colorectal cancer screening. He wishes to take part but does not feel able to complete the tests, and is embarrassed to ask anyone else. He had made an informed choice to take part but is unable to do so.

\section{Scenario 3}

A young female is invited for cervical screening, reads all the information, but is agoraphobic. She feels informed, wishes to attend, but is not able to do so.

\section{Scenario 4}

A middle aged woman is invited for cervical screening. She has read all the information, and has decided that she does not want to be screened. She gets flu and goes to see her GP whom she respects. He is very pro-screening and notices that she has not been screened. He tells her she should be screened, he can do it there and then, and she feels unable to refuse.

\section{Scenario 5}

A middle aged woman decides not to go for screening for breast cancer. Her friends are horrified and persuade her to go along with them. She was informed, had made a choice not to go, but the influence of family and friends made her go.

\section{MEASURING INFORMED CHOICE}

In attempting to measure and understand informed choice in cancer screening three assumptions are made. The first assumption is that informed choice is an important aspect of a screening programme. We accept that there is a potential inconsistency in promoting informed choice within a public health policy; personal autonomy is competing with the greatest benefit for the greatest number. However, policy makers and screening programme organisers in the UK have already decided that promoting informed choice in cancer screening is important. Therefore, this paper aims to explain how such a policy should be evaluated and measured.

The second assumption is that informed choice should be measured, rather than just accepted that it is a good thing. Measuring informed choice may set too high standards which are unachievable in practice. However, it does have important benefits: it encourages health professionals to be accountable, and it defends people from unwanted interventions and from deception and coercion. ${ }^{1}$ 
The third assumption is that informed choice can be measured in a meaningful way. This assumption is open to debate; concepts such as consent and choice are understood in contradictory ways when people rely on different theoretical models. For example, positivism defines informed choice through dichotomies: informed/uninformed, choice/ no choice. ${ }^{1}$ It is accepted that no measure of informed choice will be perfect, but this paper is the first stage in attempting to operationalise the concept.

\section{Uses of a measure of informed choice}

There are several ways a measure of informed choice in cancer screening could be used. Firstly, it could be used as an outcome measure in trials. Recently trials evaluating the effectiveness of informed choice interventions for cancer screening have been undertaken. ${ }^{22-25}$ However, many of these trials only measure knowledge and uptake, and not informed choice. A measure of informed choice in antenatal screening has already been developed, but this is not appropriate to use in cancer screening. ${ }^{26}$

Secondly, if the aim of organisations such as the NSC is to promote informed choice in populations eligible to be screened, then it is important to measure the extent to which the aim has been achieved. Informed choice, even though it might be a very important outcome to be measured in preventative care, is much more difficult to measure than coverage or uptake. ${ }^{27}$ Thirdly, as mentioned previously, it can also ensure accountability of screening programmes and act as an aid to ensuring that people are neither deceived nor coerced.

This paper describes some of the important aspects to be considered when measuring informed choice in cancer screening. These aspects of informed choice may be important in other areas of healthcare. It is likely that a wide range of strategies would need to be considered in operationalising any measurement of informed choice (questionnaires, interviews, and so on), which would need to work within system constraints at different levels-that is, constraints on the screening programme, primary care, and the health service. Items for the questionnaire should be derived from focus group discussions, individual interviews, expert opinion, and guidelines (for example, the GMC guidelines ${ }^{2}$ ) When measuring informed choice using such a questionnaire, the following factors need to be considered:

\section{How informed the person is when making their choice}

As discussed previously, if the objective of any intervention or health policy is to increase informed choice, then it can be argued that there are at least two prerequisites: (1) the provision of unbiased, up to date, relevant information on the consequences of the choice(s) and (2) the ability of the person to make an autonomous choice between more than one option. When assessing how well informed a person is, two issues need to be taken into consideration. Firstly, the different perspectives of what is deemed to be well informed, and secondly the context of the decision. For example, in countries where healthcare is not free, people might wish to have information on possible costs of treatments before considering themselves well informed.

It is not expected that, to be considered informed, people will be required to recall detailed amounts of information and figures about a screening test. As previous research has suggested, about $50 \%$ of people cannot recall significant information provided to them in relation to a consent given just a short time before. ${ }^{28}$ However, it is reasonable to expect that people have an understanding about issues such as the disease being screened for, the screening test, and the consequences of participation or non-participation. At the present time, many people have only a basic understanding of what screening is about and have little or no understanding of limitations, risks, and consequences.

\section{Preferred and/or intended choice}

A person's preferred and/or intended choice should ideally be measured after they have received their invitation to be screened but before they carry out the behaviour.

\section{Barriers towards carrying out the choice}

These may be personal or organisational barriers. Personal barriers may include physical or mental health problems and language. Organisational barriers could include availability of the service/intervention, and access.

\section{Values and beliefs}

A person's underlying values and beliefs regarding the choices may be important. ${ }^{26}$ Theories of health behaviour such as the Theory of Planned Behaviour and the Health Belief Model may be useful in developing questions. The relation between knowledge, understanding, and a person's beliefs can then be explored. For example, a person's belief that screening is "a good thing" may be based on information they have received on the benefits of screening.

\section{Degree of preferred involvement}

There is evidence that some people do not wish to be involved in making decisions about their care. ${ }^{29}{ }^{30}$ Therefore it may be important to evaluate to what extent people wish to make a choice about screening. For example, they may wish to be informed, but have the choice made by someone else, or they might decide to have little involvement in screening at all and throw away the invitation.

\section{Degree of coercion or control}

The measure should ideally include the degree to which the choice was perceived to be subject to control or coercion, although this may be difficult to tease out in practice. Understanding the process by which people arrive at this point may give insights into this issue.

\section{Perceived availability of choice}

The measure should also attempt to measure the degree to which different options were available, as perceived by the recipient. For example, people may feel that they do not have the choice to refuse screening, even though they might wish to. This is important to measure in order to distinguish between informed compliance and informed choice (as discussed previously).

\section{Behaviour carried out}

Whether screening was undertaken or not is important to measure in order to ascertain if there is a difference between the original choice and the final behaviour. The screening behaviour should be ascertained from screening records, rather than by self report.

\section{CONCLUSIONS}

Informed choice is not just about the provision of relevant up-to-date information, it is also about making sure that the appropriate choices are available to people, and that the choice is autonomous and free from coercion. It should also be recognised that, even with the best of intentions, there are extraneous, unpredictable factors which will prevent people from performing a behaviour which is in keeping with their preferred choice. Thus there may be differences between the intended choice and the final behaviour. This difference needs to be taken into account when designing a measure of informed choice, before we can be sure of the impact of informed choice on uptake or other desired endpoints. 


\section{Authors' affiliations}

R G Jepson, D Weller, Division of Community Health Sciences-General Practice, University of Edinburgh, Edinburgh, UK

J Hewison, Academic Unit of Psychiatry and Behavioural Sciences,

School of Medicine, University of Leeds, Leeds, UK

A G H Thompson, School of Social and Political Studies, The University of Edinburgh, Adam Ferguson Building, Edinburgh, UK

Sources of support: Chief Scientist Office, Scotland

\section{REFERENCES}

1 Alderson P, Goodey C. Theories of consent. BMJ 1998;317:1313-15.

2 Austoker J. Gaining informed consent for screening. Is difficult-but many misconceptions need to be undone. BMJ 1999:319.722-3.

3 Raffle AE. Informed participation in screening is essential. $B M$ 1997;314:1762-3.

4 National Screening Committee. Second report of the National Screening Committee, 2000. Available at http://www.nsc.nhs.uk/library/lib_ind.htm (accessed 12 January 2005).

5 General Medical Council. Seeking patients' consent: the ethical considerations. London: General Medical Council, 1999.

6 Anderson CM, Nottingham J. Bridging the knowledge gap and communicating uncertainties for informed consent in cervical cyłology screening; we need unbiased information and a culture change. Cytopathology 1999;10:221-8.

7 Hall SA. Should public health respect autonomy? J Med Ethics 1992; 18:197-201

8 Roberts MJ, Reich MR. Ethical analysis in public health. Lancet 2002;359:1055-9.

9 Raffle AE. Information about screening-is it to achieve high uptake or to ensure informed choice? Health Expect 2001;4:92-8.

10 Jepson RG, Forbes CA, Sowden AJ, et al. Increasing informed uptake and non-uptake of screening: evidence from a systematic review. Health Expect 2001;4:116-26.

11 Edwards A, Unigwe S, Elwyn G, et al. Effects of communicating individual risks in screening programmes: Cochrane systematic review. BMJ 2003:327:703-9.

12 O'Neill O. Some limits of informed consent. J Med Ethics 2003;29:4-7.

13 Hope T. Evidence-based patient choice. London: King's Fund, 1996.

14 O'Connor AM, Rostom A, Fiset V, et al. Decision aids for patients facing health treatment or screening decisions: Systematic review. BMJ 1999;319:731-4.
15 Bekker H, Thornton JG, Airey CM, et al. Informed decision-making: an annotated bibliography and systematic review. Health Technol Assess 1999;3:156.

16 Faden R, Beauchamp T. A history and theory of informed consent. New York, 1986.

17 Entwistle V, O'Donnell M. Evidence-based healthcare: what roles for patients? In: Edwards A, Elwyn G, eds. Evidence based patient choice: inevitable or impossible? Oxford: Oxford University Press, 2001:34-49.

18 Edwards A, Elwyn G. Understanding risk and lessons for clinical risk communication about treatment preferences. Qual Health Care 2001; 10:19-113.

19 Stapleton H, Kirkham M, Thomas G. Qualitative study of evidence based leaflets in maternity care. BMJ 2002;324:639.

20 Towle A, Godolphin W, Greenhalgh T, et al. Framework for teaching and learning informed shared decision making. BMJ 1999;319:766-71.

21 Elwyn G, Charles C. Shared decision making: the principals and the competences. In: Edwards A, Elwyn G, eds. Evidence based patient choice: inevitable or impossible? Oxford: Oxford University Press, 2001:119-43.

22 Davison BJ, Kirk P, Degner LF, et al. Information and patient participation in screening for prostate cancer. Patient Educ Couns 1999;37:255-63.

23 Flood $\mathbf{A B}$, Wennberg JE, Nease RF, et al. The importance of patient preference in the decision to screen for prostate cancer. Prostate Patient Outcomes Research Team. J Gen Intern Med 1996;11:342-9.

24 Frosch DL, Kaplan RM, Felitti V. The evaluation of two methods to facilitate shared decision making for men considering the prostate-specific antigen test. J Gen Intern Med 2001;16:391-8.

25 Rimer BK, Halabi S, Sugg SC, et al. The short-term impact of tailored mammography decision-making interventions. Patient Educ Couns 2001;43:269-85.

26 Marteau TM, Dormandy E, Michie S. A measure of informed choice. Health Expect 2001:4:99-108.

27 Wear S. Informed consent. Patient autonomy and clinician beneficence within health care. Washington DC: Georgetown University Press, 1998.

28 Schofield T. Evidence-based patient choice in primary health care. In: Edwards A, Elwyn G, eds. Evidence based patient choice: inevitable or impossible? Oxford: Oxford University Press, 2001:181-90.

29 Robinson A, Thomson R. Variability in patient preferences for participating in medical decision making: implication for the use of decision support tools. Qual Health Care 2001;10:134-8.

30 Thompson AGH, Rudat K, Staniszewska S, et al. Citizen involvement in health care: meanings, motivations and means. Final Report to the Department of Health (England). Edinburgh: University of Edinburgh, 2002. Available at http://www.healthinpartnership.org/publications/thompson/thompsonfinal.html (accessed 12 January 2005).

Marked in seconds, created in hours: MCQs and EMQs for Ethics, Communication and Social Sciences in Medicine

Hosted by the Universities Medical Assessment Partnership (UMAP), this is a workshop to disseminate good practice in question writing whilst also helping to incorporate ethics, communication, and social science questions into the UMAP bank. This will serve to encourage these topics to be assessed at UMAP partner medical schools who at present nclude Newcastle, Leeds, Liverpool, Manchester, and Sheffield.

Date: Monday $18^{\text {th }}$ April 2005

Timings: Lunch $12.30 \mathrm{pm}$, main workshop begins $1.30 \mathrm{pm}$, day ends $5 \mathrm{pm}$.

Place: Centre for Life, Newcastle

Presenter: Andrea Owen, UMAP Project Manager

Places are free of charge and can be booked by contacting the UMAP office by email, umap@fs1.with.man.ac.uk or telephone, 0161291 5805. See the project website for more details www.umap.man.ac.uk 